\title{
Research on the Integration Path of Urban and Rural Compulsory Education Under the Background of Urban-rural Integration
}

\author{
Wei Liu ${ }^{1, *}$, ShiQing Zhang,"* \\ ${ }^{1,2}$ School of Political Science and Law, University of Jinan, Shandong Province, China, 250022 \\ ${ }^{1 *}$ Corresponding author. Email: $1218451068 @$ qq.com
}

\begin{abstract}
The stage of compulsory education is an important part of China's education system. It is of great significance for realizing the Chinese dream of the great rejuvenation of the Chinese nation and improving the national quality in an all-round way. However, there has been a long-term unbalanced development between urban and rural areas in the stage of compulsory education. China has always paid attention to and emphasized educational equity. The report of the 19th national congress pointed out that we should promote the integrated development of urban and rural education. In order to realize the integration of urban and rural education there are many difficulties, this paper through in-depth analysis of the current urban and rural compulsory education contradictions, to find a solution to the contradiction between urban and rural compulsory education, which is conducive to our better grasp of the direction, in order to better realize the integration of urban and rural education development.
\end{abstract}

Keywords: Urban rural integration, Integration of urban and rural education, compulsory education

\section{INTRODUCTION}

The introduction and implementation of the policy of the integration of urban and rural compulsory education must have its practical significance. At present, the huge gap between urban and rural compulsory education in China has become an important factor restricting rural development. Many excellent talents leave their hometown for their children to enjoy better education, causing huge losses to the local area, and the brain drain is very serious. The integration of urban and rural compulsory education can better coordinate the imbalance of educational development between urban and rural areas, and can also play a certain role in promoting educational equity.

\subsection{The inevitable requirement of educational equity}

Educational equity is a unique problem existing in the stage of compulsory education. Good compulsory education resources are the ladder leading to high-quality high schools and universities. The fairness of compulsory education determines whether education is on the road of fairness, and also has decisive significance to realize the fairness of the whole education system. Due to the dual system of urban and rural compulsory education, there are great differences in the software and hardware of educational resources between urban and rural areas, which has become one of the major factors of the unbalanced development of urban and rural compulsory education in China. Therefore, the integration of urban and rural compulsory education is an inevitable requirement to realize educational equity.

\subsection{Inevitable requirements for Rural Revitalization}

In order to achieve rural revitalization, it requires the coordinated development of compulsory education in urban and rural areas. Only when there is a good compulsory education environment and resources in the countryside can we keep the young blood and avoid the phenomenon of "hollowing out" in the stage of compulsory education. Rural Revitalization includes not only the revitalization of industry, organization and ecology, but also the revitalization of talents and culture. The revitalization of talents and culture must be related to education. As the main body of education, teachers 
and students are the main force of Rural Revitalization.

\subsection{Inevitable measures to solve social contradictions}

As early as the 17th National Congress of the Communist Party of China, it was put forward that "realizing fairness and justice is the consistent proposition of the Chinese Communists and the major task of developing socialism with Chinese characteristics". China is also carrying out educational reform, especially in reducing students' burden and improving urban-rural educational inequality. This shows that the integration of urban and rural compulsory education is not only an important link to promote educational equity or reduce the educational gap between urban and rural areas, but also an important measure to solve a series of social contradictions, reduce the urban-rural gap and class gap, which can provide continuous dynamic support for rural construction and development.

\section{DIFFICULTIES FACED BY THE INTEGRATION OF URBAN AND RURAL COMPULSORY EDUCATION}

\subsection{There is a wide gap between urban and rural compulsory education teachers}

Cities are the product of modernization. Cities often have better resources and opportunities than rural areas. So is the comparison of teachers in the stage of compulsory education. Urban teachers are much better than rural teachers in both quantity and quality. Because of this, coupled with the nearby enrollment policy, many parents buy houses in the city early in order to let their children win at the starting line and get better education. This not only makes the gap between urban and rural teachers bigger and bigger, but also makes the gap between urban and rural students bigger and bigger. Many rural primary schools have to merge with other primary schools or be banned because the source of students is shrinking, while urban schools are crowded. The most fundamental reason lies in the imbalance of economic development between urban and rural areas. The city has better development opportunities and convenient transportation, while the countryside is relatively closed, and the low-income salary also discourages many teachers. The strength of teachers is one of the factors restricting the development of rural compulsory education, which makes the "brain drain" appear prematurely in rural areas. The integration of urban and rural education inevitably requires that cities and villages have the same or slightly different educational resources in the stage of compulsory education. The hardware such as teaching equipment can be introduced and helped. However, if the software such as teachers can not keep up, the rural education system will not be much improved. Therefore, how to retain and introduce excellent teachers for the countryside is a realistic problem we must solve.

\subsection{There are differences in parents' educational expectations between urban and rural areas}

Generally speaking, parents living in cities have higher educational expectations for their children than those living in the countryside. Many scholars at home and abroad have made statistical analysis and confirmed this conclusion. The reason for this difference is that on the one hand, urban parents have higher average education than rural parents, on the other hand, urban competitive pressure and faster pace of life than rural parents. Parents living in cities know the importance of education to life development. Not only their children, but even themselves will have "academic anxiety" about their children, They often invest more money in their children's learning to ensure that their children do not lag behind others. The pace of life in rural areas is not as fast as that in cities. In their eyes, many posts do not need high education. They give children more opportunities to learn. Few people regard children's learning as a tool and means for upward mobility across classes, and economic investment is less than that in cities. It can be said that the city is more utilitarian for children's studies, while the countryside is compulsory. Where children read, they will not give children too much pressure. It is this difference in educational expectations between urban and rural areas that leads to a growing gap between urban and rural education. An important task of the integration of urban and rural compulsory education is to change the concept of urban and rural parents for their children to accept the stage of compulsory education and abandon the theory of "learning is useless". Of course, with the expansion of college enrollment in recent years, many poor children can enter the university to change their destiny, making rural parents realize the importance of education, and their educational ideas are keeping pace with the times, but there is still a gap compared with the city.

\subsection{Rural poverty}

The unbalanced development of compulsory education in urban and rural areas is due to the unbalanced economic development in urban and rural areas. Rural areas are generally poor and their economic development is slow. Although tuition fees are exempted at the stage of compulsory education, many rural children are still forced to drop out of school and work early because they can't afford to go to school. Rural educational poverty has its complex political, economic and cultural factors. 


\section{AN EFFECTIVE PATH TO THE INTEGRATION OF URBAN AND RURAL COMPULSORY EDUCATION}

\subsection{Rational overall planning and deployment of urban and rural teachers}

A certain scale of high-quality teachers is the key to rural compulsory education out of the dilemma. Although there is a gap in economy and Geography between rural and urban areas, we can encourage excellent urban teachers to teach and help in rural areas by coordinating urban and rural teachers. Rural Revitalization needs to take the city with the township, and the integration of compulsory education needs to take the city with the township. On the one hand, through incentive policies, encourage more excellent urban teachers to go to the countryside for support, bring more advanced teaching ideas, or improve the treatment of graduates, attract more young teachers for rural education and supplement strong resources for rural compulsory education. On the other hand, to provide convenient conditions for rural teachers to improve themselves, the government builds a bridge between rural primary schools and urban primary schools, and establishes a platform for effective cooperation and communication learning, which can enable more rural teachers to enter higher-level schools for in-depth learning, So as to improve their quality and teaching ability, and better serve rural compulsory education.

\subsection{Educational resource sharing}

Compulsory education resource sharing includes learning resource sharing and teacher resource sharing. The sharing of urban and rural compulsory education resources is to regard urban and rural compulsory education as a complete system and fully mobilize all available resources to promote the common development and progress of urban and rural compulsory education. Modern society is an era of highly developed information. The role of the Internet in our daily study and life can not be ignored. This makes education break the traditional face-to-face teaching method, and online education has entered our life. The development of rural education has also ushered in an opportunity. Many rural primary school students can obtain educational resources that they did not get before through the Internet, and many primary schools have reached cooperation with some online training institutions to learn online for free in winter and summer vacation and experience the mode of online education.

\subsection{Improve and implement the management mechanism}

We should further improve and implement the management mechanism of "provincial overall planning, county-based", earnestly fulfill the government's overall responsibility, and increase support for counties with financial difficulties. At the same time, we will start the quality and balanced supervision, evaluation and identification of compulsory education, and promote the transformation of rural areas from "learning" to "learning". In the context of urban and rural integration, the entire compulsory education system must be part of social governance. We should make a good overall plan and line for the integrated development of urban and rural compulsory education, and constantly narrow the gap between urban and rural compulsory education.

\subsection{Increase funding for rural areas}

The increase of rural education funds, first, can be for rural primary schools in school building, infrastructure and other aspects of the city, so that children have a good learning environment. Second, rural primary schools can introduce advanced teaching instruments to improve teaching efficiency. Third, increasing the investment in rural education can improve the treatment of teachers and attract teachers into rural teaching, which can also reduce the "introversion" of urban teachers to a certain extent.

\section{CONCLUSION}

The gap between urban and rural compulsory education seriously hinders the development of rural areas, and is not conducive to the realization of rural revitalization. We can promote the integrated development of urban and rural education through rational allocation of teachers and increasing economic input in rural areas.

\section{REFERENCES}

[1] Shen Hongcheng. Education to the Countryside: Practice of Education Governance in a Township [J]. Sociological Research,2014, V. 29; No. 170 (02) : 90-115 + 243-244 DOI: 10.19934 / j.carol carroll nki shxyj. 2014.02.005.

[2] Zhang Qun, Xu Luyao, Qiu Huanmin. Urban-rural comparative study on the current situation of family education expenditure in the stage of compulsory education -- Taking Henan and Jiangxi as an example $[\mathrm{J}]$. Science and technology economic market, 2021 (07): 97-98.

[3] Wang Tong, SI Xiaohong. Evolution and Development of China's Compulsory education Policy in the Past 70 Years [J]. Modern Education Management,2020(06):34-40.

[4] Jin Zhifeng, PANG Lijuan, Yang Xiaomin. Distribution of compulsory education schools in 
urban and rural areas under the background of rural revitalization Strategy: Realistic problems and Path Thinking [J]. Journal of Beijing Normal University (Social Sciences edition),2019(05):5-12.

[5] Liao Qifa. The Development and Achievements of Compulsory Education in the 70 Years of New China -- And Universal Education [J]. Journal of southwest university (social science edition), 2019,45(05):5-13+197.

[6] Zhang Hai, Xu Lixin. Ways for regional research institutions to solve the problem of "rural weakness" in Education [J]. Beijing Education (General Education Edition), 2021 (05): 41-43. 